\title{
Spatial pattern of variation in populations of Acacia nilotica in semi-arid environment
}

\author{
${ }^{1}$ S. Mahmood, ${ }^{1}$ A. Ahmed, ${ }^{2}$ A. Hussain and ${ }^{3 *}$ M. Athar \\ ${ }^{1}$ Institute of Pure and Applied Biology, Bahauddin Zakariya University, Multan, Pakistan \\ ${ }^{2}$ Government College for Women, Vehari, Pakistan \\ ${ }^{3}$ California Department of Food and Agriculture, 1220 N Street, Sacramento, USA
}

\begin{abstract}
Variability among populations was analyzed in five provenances of Acacia nilotica from spatially variable habitats. Populations of $A$. nilotica developed in response to their habitat conditions. The level of variability was significantly high among the populations. Phenotypic variability was extremely high for leaf and stipular spine characteristics. The nature of morphological variability for vegetative traits appeared environmentally controlled. The differentiation of leaf and stipular spine expression seems to have an adaptive significance for the species in terms of water economy. Although, seed and pod characteristics are genetically controlled showing a lower proportion of variability but these traits supported $r$ and $k$-selection that may allow the species to survive under a wide array of contrasting habitats. The study suggested that populations of $A$. nilotica are differentiated in relation to the heterogeneity of environment. These populations became adapted to their habitat through the variability of morphological expressions. The morphologically differentiated populations of the species had allowed them to maintain themselves in a wide array of environmental situations enabling $A$. nilotica to occupy ample ecological ranges.
\end{abstract}

Key words: Acacia nilotica, spatial pattern, population variation, environmental adaptations

*Corresponding Author, E-mail: atariq@cdfa.ca.gov

\section{Introduction}

Spatial and temporal heterogeneity of the environment is well documented. The habitat may vary due to the changing pattern of soil chemistry, water and nutrient availability, light and many other factors (Schmitt, 1993). Plants cope with the variability of their environment. They have to endure whatever environment offers to them because of their sessile nature. Species with wide geographic ranges always develop locally adapted plant populations and show variation for morphological expressions (Elberse et. al., 2003). The species of diverse habitats may show several modifications of various morphological traits (Thompson, 1990, Thompson and Rabinowitz, 1989). This differentiation is usually pertinent to habitat conditions. Morphological variation is strongly influenced by various environmental factors. The morphological variability signifies the adaptation of the species to its environment and it may be genetically determined or environmentally induced. Thus morphological differentiation seems to have an evolutionary significance that results in the gradual adaptation of the species to its environment (Hussain and Mahmood, 2004; Mahmood and Abbas, 2003).
Acacia is a large species complex and is represented by 900 species. A. nilotica has considerable variation with its nine subspecies presently recognized, three occurring in subcontinent and six occurring throughout the Africa (Ali, 1973). The morphological variability can be extremely high in those species that have wide geographic distribution. A. nilotica has wide ecological amplitude and is found growing in a variety of habitats. The species is remarkably variable for various morphological expressions such as leaf, stipular spine morphology, pod and seed characteristics. The populations of the species can be differentiated even at a very short distances.

The main objectives of the study were to reveal differentiation among populations in relation to heterogeneous environmental situations. Study was also aimed at testing the hypothesis that populations are adapted to their environment through the variability of morphological expressions. The study focused on recognizing the pattern of morphological variability that allows a species to grow under a wide array of habitat situations. Particular attention was paid to understanding the way by which species is maintained in nature and occupy wide geographical ranges. The research was 
conducted at the institute of pure and Appiled Biology, Bahauddin Zakariya University, Multan, Pakistan durimgApril 2004.

\section{Materials and Methods}

A field study was conducted during April 2004 to study morphological variation in five populations of $A$. nilotica from five edaphically, topographically and climatically variable sites of Pakistan. Detail of the study sites is provided in Table 1 . These sites showed remarkable differences among them regarding the climate, topology, soil conditions, type and number of plant species growing and water availability. The sites were visited and observations were made for the stands of $A$. nilotica growing under natural environment. Ten individuals were selected from each site and five uniform branches were collected from each individual tree. Observations were also made for general characteristics of Acacia trees such as height and extent of branching.

\section{Collection protocols}

A. nilotica trees of uniform age were selected by measuring the girth of the plants to assess the age. Plants of uniform size within one kilometer range were sampled almost at the same time of the year from all populations. The branches were sampled at the same height of the individual trees. For morphometric analysis (leaflet length, pinnules length, spine length pod length and seed size) consistent measurements were taken. Data were analyzed statistically using analysis of variance procedures, and means were compared with the LSD multiple mean comparison test at $\mathrm{P} \leq 0.001$ unless otherwise stated. of compound leaves (Table 2). The highest number of compound leaves was observed in population at Dera Ghazi Khan while population at Multan had the lowest number of compound leaves. Populations at Vehari and Islamabad did not show any marked difference between them. Population at Sargodha had significantly reduced number of leaves than the other populations. Analysis of variance revealed a significant $(\mathrm{P} \leq 0.05)$ contrast among populations (Table 3 ).

\section{Number of leaflet per compound leaf}

Number of leaflet of A. nilotica in populations at Dera Ghazi Khan, Vehari and Islamabad were higher but did not differ significantly (Table 3). Populations sampled from different sites showed significance difference $(\mathrm{P} \leq 0.001)$ between them (Table 3$)$. The lowest number of leaflets in population at Sargodha showed a remarkable difference from all other populations. Similarly, population at Multan having lower number of leaflets also differed considerably from all other populations.

\section{Leaflet length}

Length of the leaflets of $A$. nilotica in various populations showed a significant $(\mathrm{P} \leq 0.001)$ difference (Table 3). A considerable reduction in leaflet length was observed at Multan. Other populations exhibited a variable length of leaflets (Table 3).

\section{Number of pinnules per leaflet}

Pinnule number varied considerably in a range of 17-32 pinnules per leaflet in populations of $A$. nilotica (Table 2). All populations showed significantly different number of pinnules. The two populations (Dera Ghazi

Table 1: The general description of the study sites of Acacia nilotica

\begin{tabular}{|lll|}
\hline \multicolumn{1}{|c}{ Sites } & \multicolumn{1}{c|}{ Location } & \multicolumn{1}{c|}{ General habitat conditions } \\
\hline 1. Dera Ghazi Khan & $30.10^{0} \mathrm{~N}, 70^{\circ} \mathrm{E}$ & $\begin{array}{l}\text { Sandy soil, low water availability, rain fed area, } \\
\text { ground water brackish, non- irrigated field }\end{array}$ \\
2. Multan & $30.15^{0} \mathrm{~N}, 72.25^{\circ} \mathrm{E}$ & $\begin{array}{l}\text { Soil sandy, rain fed area, ground water non saline, } \\
\text { non-irrigated soil } \\
\text { 3. Vehari }\end{array}$ \\
$\begin{array}{l}\text { S. Sargodha } \\
30^{0} \mathrm{~N}, 72^{0} \mathrm{E}\end{array}$ & $32^{0} \mathrm{~N}, 71^{0} \mathrm{E}$ & $\begin{array}{l}\text { Dry, hard and stony ground, brackish ground } \\
\text { water, non-irrigated } \\
\text { Mountainous slope, ample rainfall, soil with } \\
\text { greater organic matter content }\end{array}$ \\
\hline
\end{tabular}

\section{Results}

\section{Foliage traits}

Number of compound leaves per $20 \mathrm{~cm}$ branch

The results for number of compound leaves showed that all populations had significantly different number
Khan and Vehari) had significantly higher number of pinnules but did not show any significant differences among them. The highest number of pinnules was observed in population at Islamabad. The lowest number of pinnules was in population at Sargodha. 
Number of pinnules per leaflet was significantly different $(\mathrm{P} \leq 0.001)$ between populations at various locations (Table 3 ).

\section{Pinnule length}

A. niloltica populations showed a significant difference for pinnule length except in the population sampled from populations at Multan and Sargodha. Population at Vehari had the longest pinnules while populations at Multan and Sargodha had more expanded leaflets. The statistical analysis revealed a significant $(\mathrm{P} \leq 0.001)$ difference for pinnule length in populations that were sampled from spatially variable habitats (Table 2).

\section{Stipular Spine Traits}

\section{Number of stipular spines per $20 \mathrm{~cm}$ branch}

A significant $(\mathrm{P} \leq 0.001)$ difference was observed for number of stipular spines per $20 \mathrm{~cm}$ branch. Number of stipular spine showed responses of the populations (Table 2). However, no significant difference was observed for populations at Multan and Vehari as they had different number of spines. The occurrence of spines was more frequent for population at Sargodha that had a striking dissimilarity from all populations sampled from different sites.

\section{Stipular spine length}

All the populations of $A$. niloltica showed a significant $(\mathrm{P} \leq 0.001)$ difference for stipular spine length (Table3). The populations at Multan, Vehari and Islamabad had invariably lower mean values. However, population at Sargodha had the longest spines and differed significantly ( $\mathrm{P} \leq 0.001)$. Population at
Islamabad that had the shortest spines also showed a marked difference $(\mathrm{P} \leq 0.001)$.

\section{Pod and Seed Traits \\ Pod length}

Pods length of $A$. niloltica at various populations exhibited invariably different means for fruiting trait (Table 3). Although the population at Multan had the shortest pods but it did not differ significantly from all other populations. Population at Dera Ghazi had the longest pods but the variability of the trait was statistically insignificant (Table 2).

\section{Number of seeds per pod}

Number of seed per pod was considerably variable in different populations of A. niloltica (Table 2). However, the populations at Vehari and Sargodha had similar seed number. Population at Dera Ghazi Khan had the maximum number of seed whereas population at Multan had the lowest number of seeds. The responses of populations were distinct except the two populations (Dera Ghazi Khan and Islamabad), which had invariably same number of seeds in their pods (Table 3).

\section{Seed size}

A significant $(\mathrm{P} \leq 0.001)$ variability in seed size of $A$. niloltica was observed among all the populations. The seeds sampled from population at Vehari were larger in size in contrast to the seeds of the population at Islamabad (Table 2). The seeds from other three populations also displayed a significant difference for seed size.

\section{Discussion and Conclusion}

A considerable morphological variation was observed in five populations of A. nilotica sampled from five edaphically different sites.

Table 2: Over all mean values for various morphological attributes of Acacia nilotica sampled from different sites

\begin{tabular}{|lccccc|}
\hline \multicolumn{1}{|c|}{ Populations } & & & & \\
\hline \multicolumn{1}{|c}{ Attributes } & $\begin{array}{c}\text { Dera Ghazi } \\
\text { Khan }\end{array}$ & Multan & Vehari & Sargodha & Islamabad \\
\hline Number of compound leaves per 20 cm branch & $20.74^{\mathrm{a}}$ & $14.34^{\mathrm{b}}$ & $19.54^{\mathrm{a}}$ & $16.24^{\mathrm{b}}$ & $19.12^{\mathrm{a}}$ \\
Number of leaflets per compound leaf & $9.48^{\mathrm{a}}$ & $5.44^{\mathrm{b}}$ & $9.52^{\mathrm{a}}$ & $4.80^{\mathrm{c}}$ & $9.24^{\mathrm{a}}$ \\
Leaflet length (cm.) & $2.30^{\mathrm{a}}$ & $1.62^{\mathrm{b}}$ & $3.11^{\mathrm{c}}$ & $1.89^{\mathrm{d}}$ & $2.76^{\mathrm{e}}$ \\
Number of pinnules per leaflet & $29.76^{\mathrm{a}}$ & $19.84^{\mathrm{b}}$ & $29.54^{\mathrm{a}}$ & $17.72^{\mathrm{c}}$ & $32.56^{\mathrm{d}}$ \\
Pinnules length (cm.) & $0.42^{\mathrm{a}}$ & $0.33^{\mathrm{b}}$ & $0.68^{\mathrm{c}}$ & $0.33^{\mathrm{b}}$ & $0.49^{\mathrm{d}}$ \\
Number of spines per 20 cm branch & $11.48^{\mathrm{a}}$ & $7.00^{\mathrm{b}}$ & $7.26^{\mathrm{b}}$ & $16.26^{\mathrm{c}}$ & $1.58^{\mathrm{d}}$ \\
Length of spines (cm.) & $0.31^{\mathrm{a}}$ & $0.17^{\mathrm{b}}$ & $0.15^{\mathrm{c}}$ & $2.58^{\mathrm{c}}$ & $0.03^{\mathrm{bd}}$ \\
Length of pods (cm.) & 15.54 & 13.02 & 15.05 & 14.09 & 14.89 \\
Number of seeds per pod & $11.30^{\mathrm{a}}$ & $8.54^{\mathrm{b}}$ & $9.12^{\mathrm{c}}$ & $8.80^{\mathrm{c}}$ & $9.84^{\mathrm{d}}$ \\
Seed size (cm.) & $0.69^{\mathrm{a}}$ & $0.834^{\mathrm{b}}$ & $0.90^{\mathrm{c}}$ & $0.744^{\mathrm{d}}$ & $0.55^{\mathrm{e}}$ \\
\hline
\end{tabular}

*Means sharing the same letter do not differ significantly 
Table 3: Analysis of variance for various morphological attributes of Acacia nilotica

\begin{tabular}{|lccc|}
\hline \multicolumn{1}{|c}{ Attributes } & Mean square values & F-Values & Significance \\
\hline Number of compound leaf per $20 \mathrm{~cm}$ Branch & 69.06 & 3.72 & $*$ \\
Number of leaflets/compound leaf & 55.92 & 30.74 & $* * *$ \\
Leaflet length & 3.75 & 25.91 & $* * *$ \\
Number of pinnules per leaflet & 440.34 & 25.88 & $* * *$ \\
Pinnule length & 2.16 & 6.68 & $* * *$ \\
Number of stipular spine per 20cm branch & 301.34 & 23.80 & $* * *$ \\
Stipular spine length & 117.40 & 14.08 & N.S. \\
Pod length & 9.26 & 2.18 & $* *$ \\
Number of seeds per pod & 12.27 & 5.48 & $* * *$ \\
Seed size & 0.07 & 2.48 & $*$ \\
\hline
\end{tabular}

$*, * *, * * *$ Indicate significance at $\mathrm{P}<0.05,0.01$, and 0.001respectively. N.S.=Non-Significant

A. nilotica populations represented ample phenotypic variation from a wide array of environments. The pattern of morphological variation varies among sites particularly for leaf and stipular spine. Schmid and Weiner (1993) reported that the variability of morphological expressions could be related to their habitat types.

The differentiation of phenotypes may result from local variation of the environment, therefore phenotypic differentiation can be used as an indicative of environmental situations. Thus, those populations that occupy similar habitat might show parallel expressions. A. nilotica is an exceedingly variable tree and the characteristic growth forms are attributed to the abundance of foliage (Ali, 1973). Thus it may give an individual a characteristic appearance in the field. The individuals with greater number of compound leaves appeared as expanded trees while those having scanty foliage may have a bushy appearance. A. nilotica trees sampled from Multan and Islamabad appeared distinct for their shape. The former had well-developed individual trees while the later exhibited more bushy appearance. A nilotica trees from Dera Ghazi Khan had greater leaf number but did not exhibited extensive growth forms. Therefore, there seems to exist an incoherent pattern between foliage and growth form for thesepopulations. Hence, an inconsistent relationship between foliage abundance and growth forms is in agreement with the observation of Cody (1989), who reported different growth forms in the same species of A. aneura sampled from different sites.

There was no significant difference in number of leaflets per compound leaves between populations at Dera Ghazi Khan, Multan and Islamabad. The populations of A nilotica showed uniformity on these sites. However, populations at Vehari and Sargodha showed a considerable difference in leaflets number though population at Sargodha had significantly fewer leaflets. The individuals of this provenance constituted a distinct group or population. Plant species of diverse habitats are characterized by variable leaf morphology including both the leaf number and size, as these traits are pertinent to the sustainability of water supply (Bazzaz, 1996; Roy and Mooney, 1982).

Population at Vehari was in the vicinity of an irrigated area and ground water was also readily available to plants. Therefore, the evaporative demand through leaf surface should be greater but this provenance exhibited lower leaf number. The water availability was less at Dera Ghazi Khan, Multan and Islamabad but these provenances had more leaves. Hence, any adaptive change for leaf number in relation to water supply cannot be ascertained for these populations. However, the microsites for population at Islamabad represented an extreme contrast for water availability, as it was a stony foothill. The lowest number of leaf for this population might have a selective advantage that is optimizing water loss in a water deficit environment. Muunns (2002) had reported fewer leaves as an adaptive character under to moisture deficit conditions. The provenances were found differentiated for number of pinnules. The pattern of differentiation seems consistent with number of leaflet per compound leaf in all populations. Population at Islamabad had the highest number of pinnules on their leaflets.Populations at Dera Ghazi Khan and Multan also exhibited similar morphology for this attribute. Population at Vehari and Sargodha showed a marked 
difference between them as the later had the lowest number of pinnules on each leaflet. Again, this character appeared to be relevant to habitat situations. The differentiation pattern for number of pinnules can be explained in terms of water availability and evaporative potential. Population of $A$. nilotica at Vehari growing at the soil type that can retain greater moisture had greater number of pinnules, while reverse is true for population at Sargodha that was growing in a moisture deficit environment. Therefore, the phenotypic differentiation can be accounted for water availability. The change in pinnules morphology might have significance for the evolution of the species in a wide array of environmental conditions. These assumptions can be supported by the observations of Bazzaz (1996) and Crawley (1997), who emphasized that those species that can accommodate the variable environment can certainly have wide ecological distribution. A. nilotica has bipinnate leaflets, important photosynthetically as net carbon assimilation takes place in small pinnules present on the leaflets. Thus, the presence of greater size of the pinnules may provide two folds advantages. Larger pinnules can be photosynthetically more active because they might possess greater amount of mesophyll tissue or they may provide more expanded surfaces for rapid transpiration if it is needed. Although, net assimilation rates were not determined in populations studied here but the differentiation of pinnules in populations can imply an adaptive advantage in terms of water economy by decreasing overall transpiring surfaces particularly in a water limited habitat. This is particular true for $A$. nilotica population at Sargodha, where an affirmative correlation was observed for pinnules number and size. Similar observations have been made by Cody (1989). In situations where evaporative demands are high, greater number and size of leaf accomplish more expanded surfaces. By contrast, in population at Islamabad the pinnules were of smaller size but their number was greater. The adaptation of the populations to its environment seems achieved by variable pinnules morphology where reduction in transpiring surfaces has compensated by an increase in number of pinnules. Although, these two traits are expected to be highly correlated but the inconsistency for pinnules number and size can be explained in the light of work reported by Coaldrake (1971), who demonstrated an independent pattern of differentiation even for correlated characters on account of the variability of each microsite that influenced inconsistently different traits. Therefore, an incoherent differentiation pattern can result even for associated characters.
The differences between populations were significant with respect to the number of stipular spines present per $20 \mathrm{~cm}$ branch of the species. The number of the spine varies greatly and a significant difference was observed in all provenances except populations at Multan and Vehari where spine number was lower. Morphological variability for stipular spine has been well documented in Acacia species, where expressions of stipular spines (number and size) signify the resistance of a species to desiccation, transpiration and heat transfer. The variability of such traits must significantly modify the physiological capabilities of plants, its seasonal photosynthetic rates, and potential to survive under different moisture conditions. Cody (1989) indicated that larger differences in transpiration rate are due to the profusion and extent of spines and reported a negative relation between these two variables and transpiration.

The number and size of the spines of $A$. nilotica were significantly higher for population at Sargodha as the terrain of this site possessed a marked dissimilarity from the all other sites. The site of population at Islamabad, which receives ample rainfall each year, showed the lowest values for these two attributes. Therefore, considerable modification of spines in population at Sargodha seems to provide some means of adaptation to the species in terms of water conservation. A. niltica population at Islamabad also showed altered responses with respect to their habitat and had a few spines, as there is no need for resistance to desiccation. Independent study also demonstrated that the morphology of stipular spine varies in areas, which receives different rate of precipitation.

Floral and fruiting traits appeared to be under genetic control therefore, are less liable to change (Schmid and Weiner, 1993), while certain character expressions (vegetative) may evolve very quickly in response to the variability of habitat and seems likely to be environmentally controlled. Consequently, variation in relation to different habitat situations can only be observed for the class of expressions, which are more prone to environmental changes. Thus genetically controlled expressions may not show any differentiation despite the variability of the environment (Jasienski, et al., 1997). A. nilotica populations were not distinguished with respect to their pod morphology and all provenances exhibited similar pattern of differentiation. Although the population at Vehari had the shortest pods but it has not shown any significant difference from all other populations. These results are 
in close agreement to many researchers who regarded fruiting characters as genetically controlled rather than environmentally induced. Therefore no significant variability for this attribute was observed even from contrasting sites. The response of the populations was variable with regard to seed number and size. Seed number and size were significantly different between populations. Although both seed attributes are genetically determined but the responses of populations were significantly variable.

Nevertheless, selection seems to be operative for seed characteristics for the maintenance of populations in a wide range of environment as argued by Thompson and Rabinowitz (1989). The greater seed number and size allow the individuals better chances of survival and competitive ability. There are two theories of $r$ and $k$-selection regarding the survival of individuals in a wide range of habitat (Crawley, 1997; MacArthur and Wilson, 1967). Within an environment where the habitat conditions are erratic, $r$-selection favors those individuals, which produce large number of progenies. Conversely in a crowded habitat $k$-selection favors those individuals, which have superior progenies.

The $r$-selection seems to occur for population at Dera Ghazi Khan where individuals of the species were privileged by the greater seed number that is favored by their large progenies. Although, there was less competition in this habitat but soil conditions for seed germination appeared to be inappropriate because of limited soil moisture, which has a crucial role in seed germination. Though population at Islamabad was growing with a number of other plant species but $k$ selection does not seem to be operative. Seed progeny did not excel for its size. These results are difficult to explain in the light of $k$-selection but the discrepancy can be explained on the basis of time course changes for seed development. There are reports that phenological changes occur on account of changing altitude where delayed flowering and fruiting have been observed (Rapson and Maze, 1994; Rapson and Wilson, 1992). Seeds of $A$. nilotica from Islamabad were collected almost at the same time as for the other populations, but this provenance occupies high altitudes. Therefore the seeds sampled from population at Islamabad might have not acquired their full size at the time of their collection thus $k$-selection can not be predicted. It may be inferred from the present study that each population of $A$. nilotica is well-adapted to its habitat through the variability of various morphological expressions.

The study suggested that populations of $A$. nilotica are differentiated in relation to the heterogeneity of environment. These populations became adapted to their habitat through the variability of morphological expressions. The morphologically differentiated populations of the species had allowed them to maintain themselves in a wide array of environmental situations enabling $A$. nilotica to occupy ample ecological ranges.

\section{References}

Ali S. I., (1973). Mimosaceae. Flora of West Pakistan., 36, 1-41.

Bazzaz F. A., (1996). Plant in changing environments: Linking physiological, population and community ecology. Camb. Univ. Press, London.

Coaldrake J. E., (1971). Variation in some floral, seed and growth characteristics of Acacia harpophylla. Aust. J. Bot., 1, 335-352.

Cody M. L., (1989). Variation and covariation within and among Acacia aneura populations. Israel J. Bot., 38, 241-257.

Crawley M. J., (1997). Plant Ecology. Blackwell Sci, Publ., Oxford. $2^{\text {nd. }}$ Ed., 87-90.

Elberse L. A. M., Van Damme J. M. M. and Vantienderen P. H., (2003). Plasticity of growth characteristics in wild barley (Hordeum spontaneum) in response to nutrient limitations. J. Ecol., 9, 371-382.

Hussain A. and Mahmood S., (2004). Response flexibility in Trifolium alexendrinum L. of phenomenon of adaptation to spatial and temporal disturbed habitat. J. Biol. Sci., 4, 380-385.

Jasienski M., Ayala F. J. and Bazzaz F. A., (1997). Phenotypic plasticity and similarity of DNA among genotypes of an annual plant. Heredity, 78, 176-181.

MacArthur R. H. and Wilson E. O., (1967). The Theory of Island Biogeography. Princeton Univ. Press, Princeton.

Mahmood S. and Abbas A., (2003). Local population differentiation in Trifolium alexandrinum $L$. in response to various disturbance regimes. J. Biol. Sci., 3, 773-781.

Muunns R., (2002). Comparative physiology of salt and water stress. Plant Cell Environ., 25, 239-250.

Rapson G. L. and Maze J., (1994). Variation and integration in rare grass Achnatherum hendersonii: Phenotypic comperison with parapatric common congeners. Can. J. Bot., 7, 693-700.

Rapson G. L. and Wilson J. B., (1992). Genecology of Agrostis capilaris (Poaceae) an invader into New Zealand. I. Floral phenology. New Zealand J. Bot., 30, 1-11. 
Roy J. and Mooney H. A., (1982). Physiological adaptation and plasticity to water stress of coastal and desert populations of Heliotropium curassavicum L. Oecologia, 52, 370-375.

Schmid B. and Weiner J., (1993). Phenotypic and genetic relationship between reproductive and vegetative mass in Solidago altissima. Evolution. 47, 61-74.

Schmitt J., (1993). Reaction norms of morphological and life history traits to light availability in Impatiens capensis. Evolution 47, 1654-1668.
Thompson J. D., (1990). Morphological variation among natural populations of Spartina anglica. In: Spartina anglica Research Review (Eds. Gray A. J.and Benham P. E. M.). HMSO, London, 26-33.

Thompson K. and Rabinowitz D., (1989). Do big plants have big seeds? Amer. Naturalist,. 133, 722-728. 